\title{
The Effect Of Organizational Culture On Employee Commitment: A Mediating Role Of Human Resource Development In Korean Firms
}

Zeinab Inanlou, Ewha Womans University, South Korea

Ji-Young Ahn, Ewha Womans University, South Korea

\begin{abstract}
The purpose of this study is to examine the effect of organizational culture defined as communication, trust, and innovative production on employees' organizational commitment. Furthermore, we explored the possibility the role of HRD (Human Resource Development) activities in mediating the aforementioned relationship. Using the national employer survey data conducted by Korean government in 2011, the results find that organizational culture, in particular, defined as better communication among superiors and subordinates, trust, and appreciation of innovation from superiors, is positively related to organizational commitment. In addition, firm's investment in HRD or employee participation in HRD would play a mediating role in influencing the relationship between organizational culture and organizational commitment. Therefore, organizational culture is a critical factor to increase workers' motivation through the participation in HRD training program, thereby increasing worker's commitment. The results provide theoretical and practical implications in HRD and its link to organizational culture in organizations.
\end{abstract}

Keywords: Organizational Culture; Organizational Commitment, Human Resource Development

\section{INTRODUCTION}

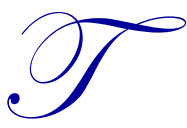

he effect of human resource activities and policies on organizational performance is an essential topic to be considered for researchers in human resource management (HRM) (Boudrean, 1991; Jones and Wright, 1992; Kleiner, 1990). Many studies have argued that there is a positive impact of human resource activities including high commitment HRM system on organizational performance (e.g., Bartel, 1994; Huselid, 1995). In a related vein, there is ample evidence to back up the claim that HRD activities among HRM practices have a positive effect on organizational performance. In practice, most organizations tend to investment more in HRD in order to increase employees' commitment. A study by Wang (2012) argued HRD activities are related to worker's full participation in HRD programs, which in turn, could lead to firm performance.

However, prior research has been paid less attention to the participation of employees in HRD activities. Specifically, some authors examined various factors such as prior information that workers receive, announcement' type that can impact employees' motivation to participate in HRD activities (Hicks and Klimoski, 1987). In this vein, some important questions remained unanswered; in what ways can managers increase impact of HRD activities or investment in HRD on employee behavior? In this study we seek answers for the mechanism through which HRD influence employee behavior such as organizational commitment, defined as psychological attachment of employees to their organization (Benkhoff, 1997; Mathieu and Zajac, 1990). The main goal of the study is to explore the possibility how firm's investment in HRD plays a role in influencing employee commitment.

In addition, we pay attention to organizational culture that influences employee behaviors within an organization (De \& Ridder, 2004) in exploring the aforementioned mechanism. Scholars argued that organizational culture has a significant impact on employees' commitment (e.g., Mathieu \& Zadjac, 1990). Building on prior research, we argue that the organizational culture could act as an important role in motivating the workers to participate in HRD activities. 
Specifically, when active communication within an organization will help employees be aware and share the information, which in turn, lead to motivate to participate in these activities. Overall, we examine the effect of communication, trust and innovative organizational culture and employee commitment, respectively. Furthermore, in examining the process of the relationship, we particularly emphasize the role of firm's investment in HRD. Put differently, how workers' participation in HRD activities can mediate the relationship between organizational culture and employees' commitment.

\section{THEORETICAL BACKGROUND AND HYPOTHESES}

\section{The Relationship Between Organizational Culture and Organizational Commitment}

Organizational culture directly impacts the way that members consciously think, make their decisions and how they view their environment around them (Hansen and Wernerfelt, 1989; Schein, 1990). Scholars posit that certain organizational culture play a critical role in shaping individual attitude or behavior (e.g., Silverthom, 2004; Schein, 1990). For example, Silverthorne (2004) suggested that bureaucratic organizational culture in Taiwan leads to the least worker job satisfaction. It seems plausible that collective culture in an organization plays an important role in the level of their workers' job satisfaction (Schein, 1990). These studies largely imply that organization should create supportive organizational culture or dynamic work culture to maintain a higher level of job satisfaction or organizational commitment.

Scholars have argued that commitment of workers is an important to increase employees' accomplishment. The rationale is the following. When employees feel they are part of the organization, such identification immediately contributes to fostering a high level of commitment and innovation. Therefore, we expect organizational culture will enhance commitment of employees. In this study, we define organizational culture based on three dimensions: communication, trust and innovation based on Denison and Mishra (1995). Then we analyze how each of dimension is related to organizational commitment.

\section{Communication}

Many researches showed ample evidence that communication is positively related to the employee's commitment (e.g., Mathieu and Zadjac's meta-analysis, 1990). For instance, De Ridder (2004) discussed that a clear internal communication could motivate supportive attitudes from employees, which in turn would lead to create organizational commitment. It is worth noting that employees will be supportive when they see themselves as shared fate within the organization when they affectively committed to (Allen and Meyer, 1996). Other researchers suggest that accuracy and transparency in communication at workplace is related to the cultivation of participation and employees' commitment (See Trombetta \& Rogres, 1988; Welsch \& LaVan, 1981). It is expected that frequent communication among supervisors and subordinates can lead to the employee attachment to organization.

\section{Trust}

Trust is defined as the belief or confidence in a person or organization's integrity, fairness and reliability (Denison and Mishra, 1995; Lipnack and Stamps 1997). It also represents 'risk-taking behavior towards the trustee' (Mayer, Davis and Schoorman 1995). Therefore, if the trust exists between parties brings the feeling which "the trusted party will not abuse or exploit the other half" (Lawler and Hackman 1975).

Studies have suggested the potential link between culture and employee attitude. For example, Dirks and Ferin (2002) showed that trust in direct leaders such as supervisors have a strongly positive relationship with organizational commitment and employees' job satisfaction. They also argued that trust in an organization can enhance employees' commitment through providing confidence that they will perform unexpectedly better in exchange of emotions such as socio-emotional development. As a result, workers emotionally attach to their organization, thereby highly committed to their organization. In addition, supportive attitudes can also be gained through trust in the management (De Ridder, 2004). Once an employee who possesses supportive attitude is likely to be committed to the organization. Thus, we expect that trust is related to build employee commitment. 


\section{Innovation}

It is expected that innovative organizational culture could increase employees' commitment. Organizational culture can affect how employees decide goals such as a personal and/or professional ones. Researchers have suggested that organizational culture influences the way individuals consciously think, create decisions and how they perceive their environment and react to it (Hansan and Wernerfelt, 1989; Schein, 1990). Other scholars have argued that innovative climate or culture is strongly related to organizations performance and commitment. For instance, innovative organizational culture and a style of leadership could have a positive effect on, both employees' job satisfaction and organizational commitment (Lok and Crawford, 2004). Specifically, it showed that the Australian managers recorded "more highly innovative and supportive culture" which had a positive effect on workers' job satisfaction and organizational commitment. Innovative and supportive cultures are more likely to be employee oriented. Moreover, employees are more likely to be supported and encouraged under the innovative culture to bring new ideas and suggestions and often time participate in formal and informal decision making (Lok and Crawford, 2004). Furthermore, coordination or concerted effort among individuals is highly emphasized under innovative culture. Consequently, employees tend to be more motivated and committed to their organization.

In sum, we first examine the relationship between organizational culture and employee loyalty to organizations. We define organizational culture as a communicated style among supervisors and subordinates, trust among employers and employees. If it is formed in an innovative manner which motivates workers to perform unexpectedly and excel through gaining higher commitment to their organization. Thus, we propose organizational culture such as having a better communication among employees and managers, trust and innovative culture will be positively related with employees' commitment. This leads to the following hypothesis;

Hypothesis 1: Organizational culture will be positively related to employee's commitment such that high communication, trust, and innovative culture is positively related to organizational commitment, respectively.

\section{The Mediating Role of Investment in HRD Activities on the Organizational Culture and Employee Commitment}

Employee training and development (generally, HRD) is most often implemented to enhance employees' knowledge, skills, and abilities (KSA). Meta-analytic results have presented some compelling evidence that training enhances performance (Arthur et al., 2003). For example, Rowold (2007) posits that HRD tend to influence employee's subsequent 'soft skills' and 'hard skills' proxied by the amount of technical training. Moreover, it shows that among HRD activities, team building is positively related to job satisfaction and organizational commitment (Neumann et al., 1989).

Relatedly, there have been numerous studies examining the effect of human resource development (HRD) training on organizational outcomes. For instance, Huselid (1995) argued the role of HRD programs on various organizational outcomes. HRD activities can enhance employees' knowledge and skills, which in turn lead to increase organizational core capabilities (Jones \& Wright, 1992, Huselid, 1997). Moreover, Osca et al (2005), have showed that firm's investment in HRD activities can signal the message to employees that human resources is highly valued, thereby increasing organizational commitment.

Likewise, firm's investment in HRD and the participation in HRD's program and activities are significantly related to employee's performance and commitment. It is expected that organizational culture, specifically aforementioned high internal communication, trust among employees and their employer as well as innovation also can increase overall motivation of employees to participate in the various human resource development activities. Building on the above hypothesis, organizational culture such as communication, trust and innovation will motivate employees to participate in human resource activities more, which in turn leads to influence organizational commitment.

In sum, organizational culture can both directly and indirectly, influence organizational commitment though employee participation in HRD activities. Put differently, participation in HRD activities mediates the link between organizational culture and individual attitudes such as organizational commitment. In this study, we define HRD activities such as education program within of the company, education program outside of the company, mentoring 
and coaching, OJT (On The Job Training), job rotation, and employee suggestion. This leads to the following hypothesis:

Hypothesis 2: Participation in HRD activities will mediate the relationship between organizational culture and organizational commitment

Figure 1. Conceptual Framework

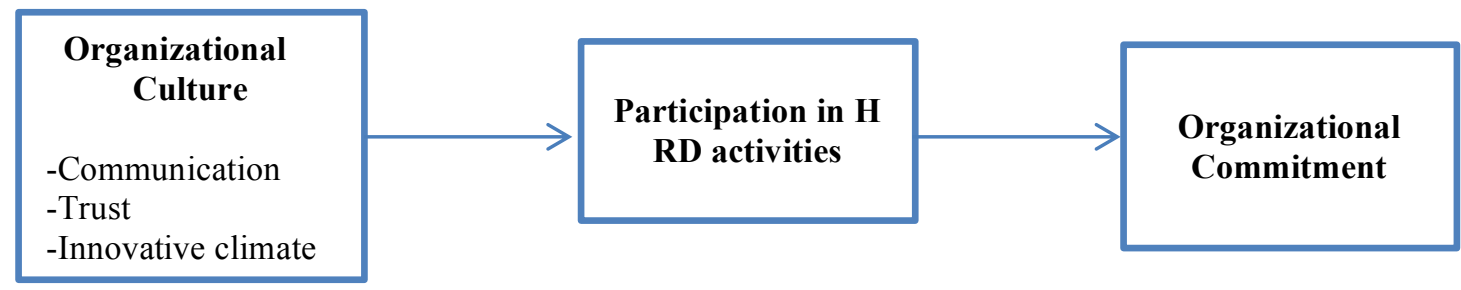

\section{METHODS}

\subsection{Sample}

The sample construction is obtained from a secondary data from Human Resource Corporate Panel. Human Capital Corporate Panel (HCCP) is publicly available nation-wide employer survey in Korea conducted by Korean government (Approval number 38903). The sample is included in companies approximately 10, 043 working employees in various sectors such as manufacturing, finance, non-finance industry in year 2011.

\subsection{Measures}

\section{Dependent Variable}

Organizational commitment is a dependent variable for the hypotheses.

Commitment of employees was measured through five-point scale with three questions about an employee' own perceptions of their loyalty within an organization building on Bae and Lawler (2002). Questions included (1) My company's problem is mine. (2) I will lose so many things if I leave the company. (3) I have loyalty to the company's value. The Coefficient Alpha was .75, being internally consistent.

\section{Independent Variables}

To capture organizational culture, we define the following three dimensions-communication, trust, and innovative climate based on prior researches (e.g., Bae and Lawler, 2002).

First, communication among employees was measured through a five-point scale with three questions that asked an employee's own perceptions of communication within an organization. The scale was (1) Not all, (2) Not really, (3) Somewhat, (4) Generally, (5) Completely. Questions included (1) Our company informs its workers about the current status of the company in detail. (2) In our company you can freely state your opinion to your superiors. (3) Our business has streamlined communication building on Bae and Lawler (2002).

Secondly, trust between superiors and subordinates was measured through five scales with three questions that asked an employees' own perception of trust within an organization. Questions included (1) In our company the workers respect one another. (2) Our company fairly assesses the work of the workers and fairly compensates them. (3) The board of directors of our company is trustworthy and good leaders being worthy of followers.

Lastly, innovation was measured through five-point scale with three questions that asked an employee' own perceptions of organizational culture within an organization. The measurement is built on Schein (1990). Questions 
included (1) Our business encourages change and innovation. (2) Our business fairly compensates innovation. (3) Our business gives more incentive to creative persons than sincere one. The Cronbach alpha for this scale was .91, implying a high internal consistency.

The mediating variable, Participation in HRD activities were measured through two-point scale with 6 questions that asked an employee's own perceptions of HRD activities' participation based on Huselid (1997). Questions includes education program within of the company, outside education program, mentoring and coaching, OJT (On The Job Training), job rotation, and employee suggestion.

\section{Control Variables}

The control variables include the individual characteristics that could potentially influence organizational commitment or organizational culture. Some demographic variables such as gender, education, and marital status had significant effects on employees' commitment (Ridd, 2004). For example, Ridd (2004) showed that males with long-term experience and high-ranking level within an organization tend to have a greater sense of commitment than others. We, therefore, included these in our model. In addition, education level directly influences the amount of time spent in various training programs (Chen \& Franceco, 2000; Salancik, 1977; Mathieu \& Zajac, 1990).

\section{EMPIRICAL RESULTS}

Descriptive statistics and correlation coefficients for all variables are reported in Table 1.

Table 1. Descriptive statistics

\begin{tabular}{|c|c|c|c|c|c|c|c|}
\hline & Mean & Sd. & 1 & 2 & 3 & 4 & 5 \\
\hline 1.Organization Culture & 3.35 & .67 & 1 & & & & \\
\hline 2.Organziational Commitment & 3.39 & .71 & $.540^{* *}$ & 1 & & & \\
\hline 3.Investment in HRD & .33 & .31 & $.200^{* *}$ & $.195^{* *}$ & 1 & & \\
\hline 4.Gender & .80 & .40 & $.100^{* *}$ & $.171^{* *}$ & $.118^{* *}$ & 1 & \\
\hline 5.Martial Status & .31 & .67 & $-.027^{* *}$ & $-.121^{* *}$ & $-.031^{* *}$ & $-.162^{* *}$ & 1 \\
\hline 6.Education & 4.97 & 1.59 & $.075^{* *}$ & $.086^{* *}$ & $.144^{* *}$ & $.046^{* *}$ & $.132^{* *}$ \\
\hline
\end{tabular}

Table 2 presents the results of factor analysis for major variables used in the study. COMM1 is "our company informs its workers about the current status of the company in detail". COMM2 is "in our company you can freely state your opinion to your superiors". COMM3 is "our business has streamlined communication". Trust 1 is "in our company the workers respect one another". Trust 2 is "our company fairly assesses the work of the workers and fairly compensates them". Trust 3 is "the board of directors of our company is trustworthy and good leaders worthy of following". INNOV1 is "our business encourages change and innovation". INNOV2 is "our business fairly compensates innovations". INNOV3 is "our business more incentive to creative person than sincere one". HRD1 is "education program within of the company". HRD2 is "education program outside of the company". HRD3 is "there is mentoring and coaching". HRD4 is "there is OJT (On The Job Training)". HRD5 is "there is job rotation". HRD6 is "there is a system of suggestions to improve the company". DV1 is "my company"s problem is mine". DV2 is "I will lose so many things if I leave the company". DV3 is "I have loyalty to the company's value" (See Table 2).

We conducted a factor analysis to ensure reliability and validity of various measurement for the study. Table 2 shows that 18 items were grouped into three parts; organizational culture, participation of HRD activities, and employee commitment to organization. The Coefficient Alpha for the three variables were .912 for organizational culture, .699 for mediator and .759 for employees' loyalty, implying a high level of internal consistency to ensure the reliability. 
Table 2. Factor Analysis

\begin{tabular}{|c|c|c|c|c|}
\hline \multirow{2}{*}{ Variable } & \multicolumn{3}{|c|}{ Factor } & \multirow{2}{*}{ Coefficient Alpha (Cronbach alpha) } \\
\hline & 1 & 2 & 3 & \\
\hline \multicolumn{5}{|c|}{ Organizational Culture } \\
\hline TRUST2 & .816 & -.073 & .153 & \multirow{9}{*}{.912} \\
\hline COMM3 & .801 & -.025 & .056 & \\
\hline COMM2 & .791 & -.046 & .107 & \\
\hline TRUST3 & .769 & -.066 & .272 & \\
\hline INNOV2 & .753 & -.107 & .206 & \\
\hline TRUST1 & .738 & -.047 & .105 & \\
\hline COMM1 & .736 & -.104 & .181 & \\
\hline INNOV1 & .674 & -.120 & .264 & \\
\hline INNOV3 & .625 & -.048 & .148 & \\
\hline \multicolumn{5}{|l|}{ Investment in HRD } \\
\hline HRD1 & -.074 & .696 & .028 & \multirow{6}{*}{.669} \\
\hline HRD2 & -.103 & .659 & .042 & \\
\hline HRD3 & -.002 & .610 & -.106 & \\
\hline HRD4 & -.108 & .577 & -.079 & \\
\hline HRD5 & .003 & .575 & .025 & \\
\hline HRD6 & -.057 & .538 & -.131 & \\
\hline \multicolumn{5}{|c|}{ Organizational Commitment } \\
\hline DV2 & .224 & -.057 & .781 & \multirow{4}{*}{.759} \\
\hline DV3 & .234 & -.069 & .758 & \\
\hline DV4 & .408 & -.083 & .745 & \\
\hline Eigenvalue & 5.324 & 2.312 & 2.068 & \\
\hline
\end{tabular}

Table 3 presents the results of the regression analysis for employees' commitment. In column (2) of the Table 3 shows that organizational culture is positively related to organizational commitment. It implies that culture in organization with better communication, high degree of trust, and highly innovative organizational climate is positively related to organizational commitment, supporting the hypothesis 1.

To examine the mediation effect of HRD participation, we conducted the Baron and Kenny (1986) methodology. First, we conducted a regression analysis between the independent variable, organizational culture, and investment in HRD in column (1) and (2). Then we conducted a regression analysis to see if organizational culture has a positive impact on employees' commitment. On the last part of the analysis, we regressed both organizational culture (independent variable) and HRD's participation (mediator) if they are positively related to employees' commitment.

It appears that HRD's participation has a partial mediation since the effect of independent variable on employees' commitment exists but the effect size has been significantly decreased from 0.550 to 0.437 based on Baron and Kenny (1986). The results support the hypothesis 2 in that participation in HRD mediates the relationship between organizational culture and employee commitment to organization. In sum, the results in Table 3 implies that organizational culture can have a positive impact on employees' commitment without having go through participation in HRD activities. Organizational culture consisted of high communication, trust, and innovative has positive impacts on, both, participation in HRD and employee's commitment.

Table 3. Results of regression analysis for employees' commitment

\begin{tabular}{|c|c|c|c|}
\hline Variables & (1) & (2) & (3) \\
\hline Constant & $0.120^{* *}$ & 1.326 & $1.345^{* *}$ \\
\hline Gender & 0.068 & 0.175 & 0.133 \\
\hline Marital Status & -0.013 & -0.101 & -0.101 \\
\hline Education & $0.025^{* *}$ & $0.025^{* *}$ & $0.020^{* *}$ \\
\hline Organizational Culture & & $0.550^{* *}$ & $0.437^{* *}$ \\
\hline HRD's participation & $0.082^{* *}$ & & $0.166^{* *}$ \\
\hline Adjusted R & 0.066 & 0.316 & 0.320 \\
\hline F value & $198.73^{* *}$ & $1159.28^{* *}$ & $948.21^{* *}$ \\
\hline
\end{tabular}

$* * \mathrm{p}<0.001$ at one-tailed test. 


\section{CONCLUSIONS}

The purpose of this study is to examine the effect of organizational culture defined as communication, trust, and innovative production on employees' organizational commitment. Furthermore, we also explored the possibility the role of HRD activities in mediating the aforementioned relationship. Using the national employer survey data conducted by Korean government in 2011, the results find that organizational culture, in particular, defined as better communication among superiors and subordinates, trust, and innovate climate, is positively related to organizational commitment.

Moreover, firm's investment in HRD or employee participation in HRD play a mediating role in influencing the relationship between organizational culture and organizational commitment. Therefore, organizational culture is an essential factor to increase workers' motivation through the participation in HRD training program, thereby increasing worker's commitment. In such a case, superiors would not be worry about their employees' mobility if they were able to build strong organizational culture within their organizations. Furthermore, the results present that participation in HRD activities partially mediates the link between organizational culture and employee's commitment. It implies that firm's investment in HRD can signal the message to employees that human resources within the organization is highly valued. Consequently, this would lead to enhance employee commitment.

Lastly, this study is not without any limitation. One is that employee responses are solely based on employee selfperception. Three variables used for this study, organizational culture, were measured based on individual perception with respect to organizational culture. In the survey, the employees' answered to the questions as to how much they think climate for the following aspects: communication, trust, and innovation. Despite its shortcoming, the results provide theoretical and practical implication in understanding the culture, HRD practices, and employee work attitudes.

\section{AUTHOR BIOGRAPHIES}

Zeinab Inanlou is a graduate student of Ewha School of Business, Ewha Womans University.

Ji-Young Ahn is an associate professor of Ewha Womans University, 52 Ewhayeodae-gil, Seodaemun-gu, Seoul 120750, South Korea. E-mail: jy-ahn@ewha.ac.kr

\section{REFERENCES}

Asted \& The Masie Center (2001). E-learning; if we build it, will they come? Alexsandira, VA: American Society for Training and development.

Bae, J \& Lawler, J. (2000). Organizational and HRM Strategies in Korea: impact on firm performance in an emerging economy. Academy of Management Journal, 43(3), 502-517.

Bartel, A. (1994). Productivity gains from the implementation of employee training programs. Industrial Relations, 33, 411-425.

Becker, B. \& Gerhart, B. (1996). The impact of human resource management on organizational performance: progress and prospects. Academy of Management Journal, 39(4), 779-801.

Chen, Z. (2000). Employee demography, organizational commitment, and turnover intentions in China: do cultural differences matter? Human Relations, 53(6), 869-887.

Delaney, J. \& Huselid, M. (1996). The impact of human resource management practices on perceptions of employee. Academy of Management Journal, 39(4), 949-969.

Denison, D. \& Mishra, A. (1995). Toward a theory of organizational culture and effectiveness. Organization Science, 6(2), 204223.

Guest, D. (2002). Human resource management, corporate performance and employee wellbeing: building the worker into HRM, Journal of Industrial Relation, 44(3), 335-358.

Hicks, D., \& Klimoski, J. (1987). Entry into training programs and its effects on training outcomes: A fiexperiment. Academy of Management Journal, 30, 542-552.

Huselid, M. (1995). The impact of human resource management practices on turnover, productivity and corporate financial performance. Academy of Management Journal, 38(3), 635-672.

Huselid, M. \& Becker, B. (1994). The strategic impact of human resources: Results from a panel study. Working paper, Rutgers University, New Brunswick, NJ.

Jarvenpaa, S. \& Leidner, E. (1999), Communication and Trust in Global Virtual Teams. Organization Science, 10, 791-815. 
Kleiner, M. \& Bouillon, M. (1988). Providing business information to production workers: Correlates of compensation and profitability. Industrial and Labor Relations Review, 41, 605-617.

Knoke, D., \& Kalleberg, A. (1994). Job training in U.S. organizations. American Sociological, Review, 59: 537-546.

Lok, P \& Crawford, L.(2003). The effect of organizational culture and leadership style on job satisfaction and organizational commitment: A cross-national comparison. Journal of Management Development, 23(4), 321 - 338.

MacDuffie, P. (1995). Human resource bundles and manufacturing performance: Flexible production systems in the world auto industry, Industrial and Labor Relations Review, 48: 197-221.

Mathieu, J. \& Zajac, D. (1990). A review and meta-analysis of the antecedents, correlates, and consequences of organizational commitment. Psychological Bulletin, 108, 171-194.

Maurer, T. \& Tarulli, B. (1994). Investigation of perceived environment, perceived outcome, and person variables in relationship to voluntary development activity by employees. Journal of Applied Psychology, 79 (1), 3-14.

Meyer, J. \& Allen, J. (1991). A three-component conceptualization of organizational commitment. Human Resource Management Review, 1, 61-89.

Morishima, M. (1991). Information sharing and firm performance in Japan. Industrial Relations, 30, $37-61$.

Noe, R. \& Wilk, S. (1993). Investigation of the factors that influence employees' participation in development activities. Journal of Applied Psychology, 78(2), 291-302.

Ridder J.(2004). Organizational communication and supportive employees. The Netherlands Human Resource Management Journal, 14(3), 20-30.

Rowold, J. (2007). Multiple effects of human resource development interventions, Journal of European Industrial Training, $33(1), 32-44$.

Silverthorne, C. (2004). The impact of organizational culture and person-organization fit on organizational commitment and job satisfaction in Taiwan. Leadership \& Organization Development Journal, 25(7), 592 - 599.

Wang, G. \& Sun, J. (2012). Theorizing Comparative Human Resource Development: A formal language approach. Human Resource Development Review, 11(3), $381-400$. 